\title{
Variety in Ancient Greek aspect interpretation
}

\author{
Corien Bary • Markus Egg
}

Published online: 17 July 2012

(C) The Author(s) 2012. This article is published with open access at Springerlink.com

\begin{abstract}
The wide range of interpretations of aoristic and imperfective aspect in Ancient Greek cannot be attributed to unambiguous aspectual operators but suggest an analysis in terms of coercion in the spirit of de Swart (Nat Lang Linguist Theory 16:347-385, 1998). But since such an analysis cannot explain the Ancient Greek data, we combine Klein's (Time in language, 1994) theory of tense and aspect with Egg's (Flexible semantics for reinterpretation phenomena, 2005) aspectual coercion approach. Following Klein, (grammatical) aspect relates the runtime of an eventuality and the current time of reference (topic time). We claim that these relations can trigger aspectual selection restrictions (and subsequent aspectual coercions) just like e.g. aspectually relevant temporal adverbials, and are furthermore susceptible to the Duration Principle of Egg (Flexible semantics for reinterpretation phenomena, 2005): Properties of eventualities must be compatible with respect to the duration they specify for an eventuality. The Duration Principle guides the selection between different feasible coercion operators in cases of aspectual coercion but can also trigger coercions of its own. We analyse the interpretations of aorist and imperfective as cases of coercion that avoid impending violations of aspectual selection restrictions or of the Duration Principle, which covers cases that are problematic for de Swart's (Nat Lang Linguist Theory 16:347-385, 1998) analysis.
\end{abstract}

Keywords Semantics - Aspect - Ancient Greek · Aspectual coercion

C. Bary

Faculty of Philosophy, Radboud Universiteit Nijmegen, Nijmegen, The Netherlands

e-mail: c.bary@phil.ru.nl

M. Egg (西)

Institute for English and American Studies, Humboldt-Universität zu Berlin, Berlin, Germany

e-mail: markus.egg@anglistik.hu-berlin.de 


\section{Introduction}

The topic of this paper is the semantics of aoristic and imperfective aspect in Ancient Greek, a language in which aoristic aspect corresponds to what is called perfective aspect in other, notably Slavic, languages. Together with the perfect, these grammatical aspects form the aspectual system of this language.

The most puzzling phenomenon about aoristic and imperfective aspect is the fact that the same verb form can get a wide range of interpretations. Aoristic aspect, for example, is often interpreted as indicating that the eventuality described is completed, but it may also be used to refer to the beginning of an eventuality. This raises the question of how these interpretations come about: Are they special instances of a basic meaning or do they constitute separate meanings? In this paper, we develop a uniform semantics for the aorist and the imperfective and show how the variation in interpretation is the result of coercion processes. Coercion refers to the reinterpretation of the argument of an operator in case of a clash between the input requirements of the operator and the properties of the argument (Moens and Steedman 1986, 1988). For aspectual coercion (or reinterpretation ${ }^{1}$ ), a very important distinction is that between bounded predicates like John eat an apple ${ }^{2}$ and John run two miles, which introduce inherent boundaries for eventualities (see Sect. 4 for details), and unbounded predicates, like John run and John be blond, which do not.

The analysis proposed in this paper shares a number of intuitions and formalisations with already existing accounts, most notably, the semantics of perfective and imperfective aspect of Gerö and Stechow (2003), de Swart's (1998) idea of coercion in this domain, and Egg's (2005) Duration Principle. After the presentation of the various interpretations of both aspects in Sect. 2, we discuss the first two accounts in Sect. 3. In Sects. 4 and 5 we combine the advantages of both into a new account of aspect, followed by a discussion of the role of the Duration Principle in Sect. 6.

\section{The data}

Both for the aorist and the imperfective there seems to be no uniform interpretation. Traditional grammars like Smyth (1920) therefore list a whole range of interpretations.

For the aorist, the interpretation depends on the boundedness or unboundedness of the predicate it is combined with. The aorist of bounded predicates indicates that an eventuality in the extension of the predicate is completed, e.g., the reception of the reign in (1). ${ }^{3}$

\footnotetext{
${ }^{1}$ We will use these terms synonymously in this paper.

2 The fact that these expressions lack inflection indicates that they do not include tense and sentence mood, roughly corresponding to VPs (including the subject) in generative approaches.

${ }^{3}$ In our glosses, we use the following abbreviations: $1=$ first person; $2=$ second person; $3=$ third person; $\mathrm{ACC}=$ accusative; $\mathrm{AOR}=$ aorist; $\mathrm{DAT}=$ dative; $\mathrm{GEN}=$ genitive; $\mathrm{IP}=$ imparfait; $\mathrm{IPFV}=$ imperfective;
} 
(1) teleutē-sa-ntos

$$
\begin{array}{lll}
\text { teleut } \bar{e}-\text { sa-ntos } & \text { Aluatte } \bar{o} & \text { ex-e-dexa-to } \\
\text { die-AOR-PTCP.GEN.SG } & \text { Alyattes.GEN.SG } & \text { from-PST-take.AOR-3SG } \\
t \bar{e}-n & \text { basilèi } \bar{e}-\boldsymbol{n} & \text { Kroiso-s } \\
\text { the-ACC.SG } & \text { reign-ACC.SG } & \text { Croesus-NOM.SG }
\end{array}
$$

the-ACC.SG

'After Alyattes died, Croesus received (AOR) the reign.'

For unbounded predicates it can have an ingressive interpretation, as illustrated by (2), which describes the beginning of joy and courage.

(2) Apotheneisk-ei

die.IPFV.PRS-3sG

Mario-s

Marius-NOM.SG

mega

great.NOM.SG

$t \bar{e}-n$

the-ACC.SG

kai

and d'

and

(...)

e-sch-e

PST-have.AOR-3SG

Rōmēen

Rome-ACC.SG

tharso-s

courage-NOM.SG

'Then Marius dies ... and immediately, great joy and courage took possession (AOR) of Rome.'

oun

then

kai

and

parautika

immediately

charma

joy.NOM.SG

Alternatively, there is a phase interpretation for the aorist of unbounded predicates (sometimes called 'complexive'; a whole stretch with beginning and end), e.g., serving a term as senator in $(3)^{4}$ :

(3)

$\begin{array}{lll}\text { alle }-n & \text { men } & \text { arch } \bar{e}-n \\ \text { other-ACC.SG } & \text { PRT } & \text { office-ACC.SG } \\ \text { oudemia- } n & \text { pōpote } & \\ \text { no-ACC } & \text { ever } & \\ \bar{e} r x a & e n & t \bar{e} i \\ \text { PST.rule.AOR.1SG } & \text { in } & \text { the.DAT.SG } \\ \text { polei, } & e \text {-bouleu-sa } & \text { de } \\ \text { state.DAT.SG } & \text { PST-be.a.senator-AOR.1SG } & \text { but }\end{array}$

'I never held any other office in the state but I served a term as senator (AOR).'

Imperfective aspect in Ancient Greek can be interpreted in various ways, too. Some instances of the imperfective express mere temporal inclusion, e.g., in (4), here the time of Lycomedes' reign includes the time introduced by the adverbial tote 'then':

\footnotetext{
Footnote 3 continued

$\mathrm{NOM}=$ nominative; $\mathrm{PL}=$ plural; $\mathrm{PRS}=$ present tense; $\mathrm{PRT}=$ particle; $\mathrm{PS}=$ passé simple; $\mathrm{PST}=$ past tense; $\mathrm{PTCP}=$ participle; $\mathrm{SG}=$ singular.

${ }^{4}$ Further uses of the aorist are the tragic and generic uses, which will not be discussed in this paper. For an account of the former in terms of performativity, see Bary (2009a; to appear).
} 
(4) e-basileu-e de Lukomēè̄-s tote t-ōn Skuri-ōn

PST-be.king.IPFV-3SG PRT Lycomedes-NOM then the-GEN.PL Scyrians-GEN.PL 'Lycomedes was at that time king (IPFV) of the Scyrians.' Plu. Thes. 35.6

Other instances are interpreted progressively, e.g., in (5):

(5) autēe to-n andr' e-thapt-e

she.NOM.SG the-ACC.SG man.ACC.SG PST-bury.IPFV-3SG

'She was burying (IPFV) the man'

Soph. Ant. 402

This is the report of a guard who has to make sure that Polyneikes' corpse is not buried. In (5) he tells what he saw after a cloud of dust had disappeared. It is clear that this woman, viz., Antigone, is caught red-handed in the middle of burial rites.

(6) illustrates an iterative interpretation of the imperfective; the sentence refers to repeated defeats of the Lacedaemonians against the Tegeans:

(6) $E$ Ei

during
basileuont-os
be.king.IPFV.PTCP-GEN.SG
en
in
all-ous
other-ACC.PL
hoi
the.NOM.PL
Tegeēt-as

gar

PRT

kai

and

Spartēi

Sparta.DAT.SG

polem-ous

war-ACC.PL

Lakedaimoni-oi

Lacedaemonian-NOM.PL

moun-ous

only-ACC.PL
Leont-os

Leon-GEN.SG

Hēgēsikle-os

Hegesicles-GEN.SG

$t$-ous

the-ACC.PL

eutucheont-es

be.successful.IPFV.PTCP-NOM.PL pros

against

pros-e-ptai-on

to.PST.bump.IPFV-3PL

Tegean-ACC.PL

'For when Leon en Hegesicles were kings of Sparta, the Lacedaemonians, while successful in all their other wars, suffered defeats (IPFV) only against the Tegeans.'

Hdt. 1.65.1

Habitual interpretations also exist, e.g., in (7), which presents a military strategy of the Persian king Cyrus:

(7) en

$\begin{array}{lllll}\text { en } & \text { dexia- } i & \text { de } & k a i & \text { en } \\ \text { in } & \text { right-DAT.SG } & \text { PRT } & \text { and } & \text { in } \\ \text { aristera- } i & \text { autou } & \text { te } & k a i & t \text {-ōn } \\ \text { left-DAT.SG } & \text { him.GEN } & \text { PRT } & \text { and } & \text { the-GEN.PL } \\ \text { hippe-ōn } & \text { peltasta-is } & \text { chōra } & \bar{e} n & \\ \text { cavalry-GEN.PL } & \text { targeteer-DAT.PL } & \text { place.NOM.SG } & \text { be.PST.IPFV.3SG }\end{array}$

'To the right and left from him and the cavalry was (IPFV) the usual place for the targeteers.'

Finally, there are conative readings, which express the attempt or wish to do something: 
(8)

\begin{tabular}{|c|c|c|c|}
\hline epethume $\bar{e}-s-e$ & $t \bar{e}-s$ & chlanidos & $k a i$ \\
\hline long.for.PST-AOR-3sG & the-GEN.SG & garment.GEN.SG & and \\
\hline$a u t \bar{e}-n$ & pros-elthōn & oneeto. & ho \\
\hline that-ACC.SG & to-go.AOR.PTCP.NOM.SG & buy.PST.IPFV.3sG & the.NOM.SG \\
\hline$d e$ & Sulosōn & $(\ldots)$ & legei: \\
\hline PRT & Syloson.NOM.SG & $(\ldots)$ & say.PRS.IPFV.3sG \\
\hline$e g \bar{o}$ & tautēe-n & pōle- $\bar{o}$ & men \\
\hline I.NOM & that-ACC.SG & sell.PRS.IPFV-1SG & PRT \\
\hline udenos & chrēmatos, & didōmi & $d e$ \\
\hline $\begin{array}{l}\text { O.GEN.SG } \\
l l \bar{Q} s\end{array}$ & money.GEN.SG & give.PRS.IPFV.1sG & PRT \\
\hline
\end{tabular}

for.nothing

'He set his heart upon the garment, came forward and wanted to buy (IPFV) it. But Syloson said: 'I don't sell that one for any money, but I give it for free."

Hdt. 3.139.2-3

\section{Previous approaches}

In the semantic literature, the distinction between perfective (=aoristic) and imperfective aspect has received considerable attention. In this section we discuss two theories, which formulated valuable insights on aspect that will be incorporated into our analysis, viz., the one of de Swart, and the one of Klein and Gerö and von Stechow. The discussion of these analyses will lead to a better understanding of the requirements for a theory of aoristic and imperfective aspect. These requirements will be formulated at the end of this section.

\subsection{Grammatical aspects select for certain predicates}

French imparfait and passé simple exhibit roughly the same range of interpretations as listed above for the Greek imperfective and aorist. However, rather than distinguishing a temporal and an aspectual operator in the semantics of these verbs forms, de Swart (1998) uses combined operators in her analysis of the French data. Her aspectually sensitive past tense operators are past tense operators that restrict the aspectual class of the predicates they combine with. More precisely, the semantics of the imparfait is a past tense operator that selects for unbounded predicates, whereas the passé simple corresponds to a past tense operator that selects for bounded predicates.

The variation in interpretation is then attributed to a coercion process. If the passé simple combines with an unbounded predicate, this predicate is reinterpreted as a bounded predicate to resolve the mismatch. The reinterpretation results in an ingressive or complexive interpretation. Similarly, the habitual and progressive interpretations of imperfective aspect are the result of the reinterpretation of a bounded predicate that is combined with the imparfait.

Coercion (aka reinterpretation) is formalised in terms of operators that map the argument (here, the predicate) onto another predicate that complies with 
the selection restrictions of the function (here, the tense operator). Consider e.g. (9):

(9) (Soudain,) Jeanne sut la réponse.

(Suddenly,) Jeanne know.PS.3sG the answer

'(Suddenly,) Jeanne knew (PS) the answer.'

Here the unbounded predicate savoir 'to know' is mapped onto a bounded predicate by means of an ingressive coercion operator which maps a predicate $P$ (here, about Jeanne's belief state) onto a predicate that expresses the beginning of $P$. This coercion process resolves the mismatch between the selection restrictions of the passé simple for bounded predicates and the unbounded predicate it combines with. Afterwards, the passé simple can be used.

This analysis works out for French because the passé simple and imparfait show up only in the past tense. In Ancient Greek, however, the aorist-imperfective distinction is not restricted to the past tense; on the contrary, it appears throughout the verb paradigm: We find distinct aoristic and imperfective forms in the subjunctive, optative, imperative, participle, and infinitive, all of which make no temporal contribution. Hence, it is not possible to reduce aspect in Ancient Greek to a temporal phenomenon.

But Bary (2009a, b) shows in detail that even if we give up the temporal part of de Swart's analysis, but hold on to the idea that the aorist-imperfective distinction can be reduced to a selection for bounded and unbounded predicates, respectively, the account still cannot be reformulated in a way that assigns a uniform non-empty semantics to the Greek aorist and imperfective: If tense cannot trigger the coercion, some other element, common to all verb forms, has to. The only possible candidate would be aspect itself, but if the sole contribution of aspect were this selection restriction, its semantics would be empty. Note that this holds not only for Ancient Greek, but for all languages in which the opposition is found throughout the paradigm, e.g., the Slavic languages.

Furthermore, there is a more general problem for de Swart's account, which shows up for French as well as for a potential application to Ancient Greek. If the special interpretations of French past tense forms and the Ancient Greek aorist and imperfective are put down to aspectual coercion only, the analysis predicts that these interpretations arise only in case of a mismatch between the requirements of the operator and the aspectual class of its argument: Reinterpretation operators can be inserted if and only if there is a conflict in aspectual class, and nothing else can trigger the coercion.

Consequently, habitual interpretations of imperfective aspect should occur only in case of a mismatch, i.e., with a bounded predicate. This prediction is not borne out; examples like (10) show that the imperfective with unbounded predicates can be interpreted habitually, too, even though there is no aspectual mismatch. (7) illustrates the same phenomenon for Ancient Greek.

(10) Quand j' étais petit, je ne dormais pas bien.

When I be.IP.1sG young I not sleep.IP.1sG not well

'When I was young I didn't sleep (IP) well.' 
In sum, the discussion of de Swart's analysis has shown that while the notion of coercion is clearly applicable to the Greek data, aspect in Ancient Greek cannot be reduced to aspectual selection restrictions. In the next section we will review aspectual theories that agree with this conclusion and attribute a semantic contribution to Ancient Greek aspect.

\subsection{Grammatical aspects indicate temporal relations}

Klein (1994) distinguishes aspectual class (or 'aktionsart') from grammatical aspect. Aspectual class is introduced by the semantics of an uninflected verb and its complements and adjuncts and describes the temporal progression of the eventuality denoted by the verb; grammatical aspect is introduced by aspectual inflection and locates the eventuality temporally with respect to the reference or topic time $\left(t_{T T}\right)$, about which a claim is made.

In detail, Klein claims that imperfective aspect indicates that the topic time is properly included in the runtime of the eventuality. Perfective aspect, on the other hand, indicates that the time of the eventuality is included in the topic time: ${ }^{5}$

(11) imperfective: $\tau(e) \supset t_{T T}$

perfective: $\tau(e) \subseteq t_{T T}$

Here $\tau$ is the function that maps eventualities onto their runtime. It is then the task of tense to relate $t_{T T}$ to the time of utterance.

This semantics is illustrated in the following example (Klein 1994):

(12) a. What did you notice when you entered the room?

b. There was a book on the table. It was in Russian.

Suppose that (12-a) is a question of a judge in a court room and (12-b) the answer of a witness. The judge's question fixes the topic time, the time about which the witness is supposed to speak. The past tense expresses that this time is in the past. According to Klein, the sentences in (12-b) have imperfective aspect and hence indicate that the lying of the book on the table and its being in Russian include the topic time.

Gerö and Stechow (2003) adopt Klein's semantics for tense and aspect and formalise it in a typed lambda-calculus. They claim that the Ancient Greek aorist corresponds to INCLUDES and imperfective to INCLUDED:

$$
\begin{aligned}
& \text { INCLUDES }=\lambda P \lambda t \exists e[\tau(e) \subseteq t \wedge P(e)] \\
& \text { INCLUDED }=\lambda P \lambda t \exists e[\tau(e) \supseteq t \wedge P(e)]
\end{aligned}
$$

$P$ is a variable for predicates of eventualities. Thus, INCLUDES and INCLUDED take a predicate of eventualities and return a predicate of times. INCLUDES, for example, maps the set of eventualities in the extension of $P$ onto the set of times that include the runtime of an eventuality of which $P$ holds. The topic time is rendered as a

\footnotetext{
5 This is based on Klein (1994:118). On pp. 99-108 he assigns perfective aspect a different temporal relation: the topic time overlaps with, but is not (properly or improperly) included in the eventuality time $\left(t_{T T} \bigcirc \tau(e) \wedge t_{T T} \nsubseteq \tau(e)\right)$.
} 
variable $t$ that remains free during semantic composition (one way of modelling intersentential anaphora in a non-dynamic framework).

But Gerö and Stechow not only integrate Klein's account into a compositional semantic framework, they try to account for the whole range of interpretations of aoristic and imperfective aspect as well. To this end, they first assume that the aspectual operators in (13) carry selection restrictions for aspectual classes. To the imperfective operator INCLUDED, they assign a selection restriction for unbounded predicates. ${ }^{6}$ For perfective aspect, they claim that it selects for bounded predicates only.

In case these selection restrictions are not met, they assume that a covert operator intervenes between operator and predicate that solves this mismatch by mapping bounded onto unbounded predicates or vice versa. Such operators include the progressive and the iterative operator, which then brings about the wide range of interpretations associated with aspect in Ancient Greek. While we agree that these interpretations are indeed due to coercion processes, their approach still leaves unanswered the question (raised already for de Swart's approach) of how to account for cases of coercion like in (7), which are not triggered by an impending aspectual mismatch.

This coercion approach is very close to de Swart's original intuitions and to what we will propose in the following section, however, there is another open question for Gerö and Stechow's account, viz., the question of where the selection restrictions for the aspectual operators come from. They claim that it follows from the semantics of imperfective and perfective aspect (from INCLUDED and INCLUDES, respectively) that imperfective aspect can only combine with unbounded and perfective aspect can only combine with bounded predicates. We feel that these claims are in need of more motivation: At first sight at least, it is not obvious why the runtime of an eventuality in the extension of a bounded predicate cannot include the topic time, or why the runtime of an eventuality in the extension of an unbounded predicate could not be included in the topic time.

To sum up the discussion in this paper, an analysis of Ancient Greek aspect must assign a nonempty semantics to both aorist and imperfective. The wide range of interpretations of aspectual operators is to be modelled in terms of aspectual coercion that is used to avoid impending violations of aspectual selection restrictions of these operators. However, more need be said about the motivation of these selection restrictions, and about the cases of coercion that are not based on these restrictions. The analysis to be developed in the remainder of this paper will answer these questions and at the same time take into account insights from previous analyses.

\footnotetext{
6 They formalise this as a selection restriction for predicates with the subinterval property or divisivity, which distinguishes bounded and unbounded predicates (Bennett and Partee 1978): Unbounded predicates have the subinterval property (at least down to a minimal threshold, see footnote 7 for details), bounded predicates do not. E.g., a part of walking still counts as walking, a part of writing a letter is not writing a letter.
} 


\section{The semantics of aspect in Ancient Greek}

In this section, we describe the semantics of aorist and imperfective in the framework of Klein (1994). Based on this analysis, subsequent sections will then expound how the wide range of interpretations associated with these aspects emerges on the basis of this semantics. In particular, this wide range is due to reinterpretation (or coercion) operators that are inserted in order to comply with the aspectual selection restrictions of aspectual operators and the Duration Principle, which requires that the information about the duration of an eventuality remains compatible.

Both aorist and imperfective are analysed as grammatical aspectual operators, which relate the runtime of a specific eventuality $(\tau(e))$ with the respective topic time $\left(t_{T T}\right)$ : The aorist states that $\tau(e)$ is an (im-)proper part of $t_{T T}$; the imperfective indicates that $t_{T T}$ is an (im-)proper part of $\tau(e)$. I.e., while the aorist can be modelled in terms of Klein's perfective operator, the Ancient Greek imperfective is slightly different from Klein's imperfective operator in that we also allow identity of $t_{T T}$ and $\tau(e)$ for reasons to be discussed in Sect. 4.2.

The operators for the two aspects apply to predicates, i.e., to properties of eventualities that are introduced by verbs and their arguments. Predicates can be grouped into different aspectual classes; the crucial distinction that we will use in the following is the one between bounded and unbounded predicates. Boundedness can be formalised as a property of predicates BD (Krifka 1989):

$$
\forall P \forall e \forall e^{\prime} \cdot \mathbf{B D}(P) \leftrightarrow P(e) \wedge e \sqsubset e^{\prime} \rightarrow \neg P\left(e^{\prime}\right)
$$

Eventualities in the extension of bounded predicates $P$ are not a proper part of another eventuality in the extension of $P$.

In this respect, we deviate from de Swart's (1998) position, in which the influence of grammatical aspect on the relation between eventuality and $t_{T T}$ is only indirect in that grammatical aspect fixes the aspectual class, and the aspectual class determines the relation between eventuality and $t_{T T}$.

In our analysis, the topic time can be formalised in terms of an anaphor. While this eventually calls for a dynamic framework which spells out the way in which $t_{T T}$ is introduced, accessed, and updated in a discourse, we do not focus on these issues and hence can make do with a non-dynamic analysis. But see Bary (2009a) for a dynamic version of the analysis proposed in this paper.

\subsection{The aorist}

While we advocate the simple distinction of aorist and imperfective sketched above and adopt it in our own analyses of Ancient Greek aspectual markers, we feel that it is in need of further qualification in order to rule out unwanted semantic overlap between the markers.

The first qualification pertains to the aorist and addresses the observation that some constellations of $t_{T T}$ and $\tau(e)$ describable by the imperfective of an unbounded $P$ could be expressed using an aorist of $P$ as well: In these constellations, the eventuality $e$ whose runtime is $\tau(e)$ has at least one part that is the runtime of a 


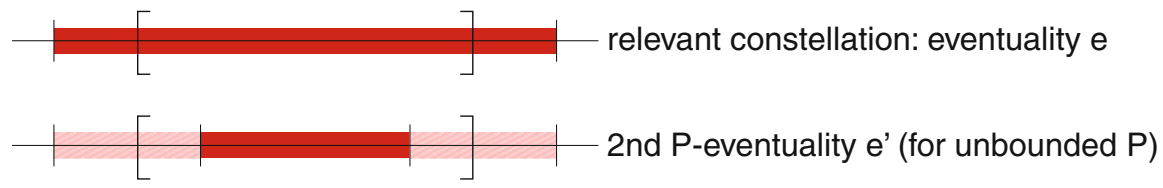

Fig. 1 Potential overlap between imperfective and aorist 1

second eventuality $e^{\prime}$ that is also in the extension of $P$, and this $e^{\prime}$ is so small that its runtime $\tau\left(e^{\prime}\right)$ is located in the topic time. Figure 1 illustrates this constellation; in this figure, the topic time is indicated by the brackets, and the runtime of the eventualities ( $\tau(e)$ and $\tau\left(e^{\prime}\right)$, respectively), by the beams.

The reason for this overlap is the divisivity of unbounded predicates, formally, a property of predicates DIV:

$$
\forall P \forall e \forall e^{\prime} . \mathbf{D I V}(P) \leftrightarrow P(e) \wedge e^{\prime} \sqsubset e \rightarrow P\left(e^{\prime}\right)
$$

Proper parts of eventualities in the extension of divisive predicates $P$ are likewise in the extension of $P{ }^{7}$ For bounded predicates, no such overlap could ever emerge for the relevant constellation in Fig. 1, because by definition no eventuality in the extension of a bounded predicate $P$ is a proper part of another $P$-eventuality.

We want to rule out the unwanted potential overlap between imperfective and aorist for unbounded predicates in terms of an aspectual class restriction. We see this restriction as a case of pragmatic strengthening, which removes semantic overlap between competing instantiations of the same grammatical feature (here, aspect). Any apparent violation of this selection restriction will then be explained in terms of aspectual coercion, see Sect. 5.

In principle, such a restriction could block a direct combination of unbounded predicates with either the aorist or the imperfective. Due to examples like (4) (stative predicates in the imperfective aspect), which show no coercion effect whatsoever, we choose the first of these options and assume a selection restriction of the aorist for bounded arguments. As a result of this pragmatically triggered selection restriction, the aorist is no longer possible for unbounded predicates in the relevant constellation of Fig. 1, which rules out potential semantic overlap between aspectual markers.

We postpone the discussion of the coercion cases to Sect. 5 and will now first show how the proposed analysis works for simple cases, like the main clause of (16) $(=(1))$ where there is no coercion since the aorist combines directly with the bounded predicate receive the reign:

$\begin{array}{llll}\text { teleutēesa-ntos } & \text { Aluatteo } & \text { ex-e-dexa-to } & t \bar{e}-n \\ \text { die-AOR-PTCP.GEN.SG } & \text { Alyattes.GEN.SG } & \text { from-PST-take.AOR-3SG the-ACC.SG } \\ \text { basilèeie }-n & \text { Kroiso-s } & & \\ \text { reign-ACC.SG } & \text { Croesus-NOM.SG } & & \end{array}$

'After Alyattes died, Croesus received (AOR) the reign.'

Hdt. 1.26.1

\footnotetext{
7 Full divisivity holds for stative predicates like be in the pub or love Mary only, which can consequently apply to minimal temporal entities like time points (if one wants to assume these); for process predicates, there is a lower bound for divisivity, they cannot apply to minimal temporal entities. E.g., eventualities of taking one step are minimal eventualities in the extension of walk.
} 
The analysis directly assigns it a completive interpretation. The aorist semantics (17-a) maps properties of eventualities $P$ onto the set of times that include the runtime of an eventuality of type $P$. Then the semantics of tenses maps a property $P^{\prime}$ of the topic time (which itself is rendered as anaphor $t_{T T}$ and which picks up the time after Alyattes' death ${ }^{8}$ ) onto a proposition. (17-b) shows this mapping for the past tense, here $P^{\prime}$ is mapped onto a conjunction of $P^{\prime}\left(t_{T T}\right)$ with the proposition that $t_{T T}$ precedes the utterance moment $t_{0}$. (17-c) states that the entire transfer of the reign to Croesus took place within the topic time, which lies before $t_{0}$ :

$$
\begin{aligned}
& \text { a. } \lambda P \lambda t \exists e . P(e) \wedge \tau(e) \subseteq t \\
& \text { b. } \lambda P^{\prime} . P^{\prime}\left(t_{T T}\right) \wedge t_{T T}<t_{0} \\
& \text { c. } \exists . \text { receive-reign' }\left(\text { croesus }^{\prime}\right)(e) \wedge \tau(e) \subseteq t_{T T} \wedge t_{T T}<t_{0}
\end{aligned}
$$

The intuition that the transfer of the reign of Croesus itself lies before $t_{0}$ is expressed in (17-c) in that its runtime (as a part of the topic time) also lies before $t_{0}$.

\subsection{The imperfective}

In this section, we will introduce the analysis of the imperfective as sketched at the beginning of Sect. 4, and then refine it slightly to make it fit in with the situation in Ancient Greek.

If one analyses the imperfective in terms of (im-)proper inclusion of $t_{T T}$ in $\tau(e)$, there is once again overlap between aorist and imperfective: This time, it is identity between $t_{T T}$ and $\tau(e)$, which is a possible constellation for both of them. Getting rid of this potential overlap by allowing identity of $t_{T T}$ and $\tau(e)$ for aorist or imperfective only would not work, because this constellation can be found in both aorist and imperfective constructions.

For unbounded predicates, identity of $\tau(e)$ and $t_{T T}$ is characteristic for participles that elaborate the eventuality $e$ as introduced by the main verb, as e.g. in (18). We follow the analysis of Bary and Haug (2011), who show that for such participles, the runtime of this eventuality $e$ determines the topic time for the participle. E.g., in (18), the speaking eventuality introduced by elalei 'he was speaking' is elaborated as a praising of God by the participle (and its object):

$$
\begin{array}{llll}
e \text {-lalei } & \text { eulogōn } & \text { to- } n & \text { theo- } n \\
\text { PST.speak.IPFV.3sG } & \text { praising.IPFV.PTCP.NOM.SG the-ACC.SG } & \text { God-ACC.SG } \\
\text { 'He was speaking (IPFV) praising (IPFV) God.' } &
\end{array}
$$

We contend that this kind of elaboration entails identical runtimes for the two eventualities $e$ and $e^{\prime}$ introduced by elaborated and elaborating constituents, respectively. For instance, the speaking and the praising in (18) are simultaneous. ${ }^{9}$

\footnotetext{
${ }^{8}$ See Bary and Haug (2011) for an analysis of the role of participle clauses in determining the topic time.

${ }^{9}$ Such entailments for discourse relations like elaboration are discussed extensively in Asher and Lascarides (2003). They assume for elaboration in general a part-of relation $\tau\left(e^{\prime}\right) \subseteq \tau(e)$, which can be strengthened to identity in the construction illustrated by (18).
} 


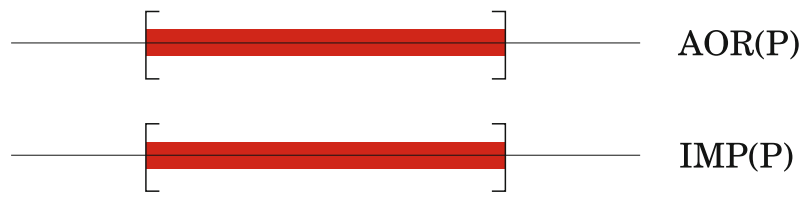

Fig. 2 Potential overlap between imperfective and aorist 2

But, then, topic time and runtime are identical for the participle in (18), and, since eulogōn 'praising' is an imperfective form (recall that morphological marking of aorist and imperfective is not restricted to finite forms in Ancient Greek), this is a clear case of an unbounded imperfective predicate, for which $t_{T T}$ and $\tau(e)$ are identical.

For bounded predicates $P^{\prime}$ in the aorist, identity of $\tau(e)$ and $t_{T T}$ also is an option. Consider e.g. cases like, where the $t_{T T}$ is a time point provided by the adverbial exaiphnēs 'suddenly'. Such a $t_{T T}$ is too short to have proper parts, which means that $\tau(e)$ can only be identical to it, but not a proper part of it:

$\begin{array}{llll}\text { (19) } K a i & d \bar{e} t & \text { epi } & t \bar{e}-s \\ \text { and } & \text { PRT } & \text { on } & \text { the-GEN.SG } \\ n e \bar{o} s & \text { anagignōskon- } t i & \text { moi } & t \bar{e}-n \\ \text { ship.GEN.SG } & \text { read.IPFV.PTCP-DAT.SG } & \text { me.DAT } & \text { the-ACC.SG } \\ \text { Andromeda- } n & \text { pros } & \text { emauton } & \text { exaiphne } \bar{s} \\ \text { Andromeda-ACC.SG } & \text { to } & \text { me.ACC } & \text { suddenly } \\ \text { potho-s } & t \bar{e}-n & \text { kardia- } n & e \text {-patax-e } \\ \text { craving-NOM.SG } & \text { the-ACC.SG } & \text { heart-ACC.SG } & \text { PST-smite.AOR-3sg } \\ \text { po } s & \text { oiei } & \text { sphodra } & \\ \text { how } & \text { think.PRS.IPFV.2SG } & \text { very.much } & \end{array}$

'And while I was on board, reading the Andromeda, suddenly a craving smote (AOR) my heart, you'll never guess how strong.'

Aristoph. Frogs, 52-54.

In sum, for constellations in which $t_{T T}$ and $\tau(e)$ are identical, there is potential overlap between aorist and imperfective as competing instantiations of the same grammatical feature. This is depicted in Fig. 2.

This time, the overlap emerges for bounded predicates only, since unbounded predicates do not meet the independently determined aspectual selection restriction of the aorist.

Once again, we are left with the choice of blocking the unwanted overlap by ruling out direct combinations of bounded predicates with either the imperfective or the aorist in terms of an appropriate aspectual selection restriction. In the light of examples like (1), which exhibit aorist forms of bounded predicates that can be interpreted directly (i.e., without coercion), we conclude that the only remaining feasible aspectual selection restriction is one of the imperfective for unbounded predicates. Such a selection restriction is stipulated in Gerö and Stechow (2003); our approach shows that this restriction can be motivated in terms of pragmatic 
strengthening, which answers an objection raised by Bary (2009a) against such an analysis. As a result, the aorist selects for bounded, and the imperfective, for unbounded predicates.

Note that this account does not depend on an ordering of the two instances of pragmatic strengthening. The potential overlap for the aorist and imperfective for bounded predicates for identical $t_{T T}$ and $\tau(e)$ must be dealt with in any case; this is not affected in any way by the question of whether there is a selection restriction of the aorist for bounded predicates or not.

For (4), repeated here as (20), this interpretation of the imperfective yields a straightforward interpretation:

$\begin{array}{llll}\text { e-basileu-e } & \text { de Lukomēdē-s tote } t-\bar{o} n & \text { Skuri-ōn } \\ \text { PST-be.king.IPFV-3SG PRT Lycomedes-NOM then the-GEN.PL } & \text { Scyrians-GEN.PL } \\ \text { 'Lycomedes was at that time king (IPFV) of the Scyrians.' } & \text { Plu. Thes. } 35.6\end{array}$

The semantics of the imperfective (21-a) maps properties of eventualities $P$ onto the property of being an (im-)proper part of the runtime of an eventuality of type $P$, which together with the interpretation of the past tense in (17-b) yields (21-b) as the semantics of (20): The runtime $\tau(e)$ of an eventuality $e$ of Lycomedes being king of the Scyrians includes the topic time $t_{T T}$ (as introduced by tote 'then'), which precedes $t_{0}$. In the larger context, the topic time is determined as the time when Theseus sailed to the island of Scyros. The semantics leaves open whether Lycomedes remains king after the topic time and whether he is king at the moment of utterance, as desired.

(21) a. $\lambda P \lambda t \exists e . P(e) \wedge t \subseteq \tau(e)$

b. $\exists e$.king-of ${ }^{\prime}\left(\right.$ lycomedes $^{\prime}$, scyrians $\left.^{\prime}\right)(e) \wedge t_{T T} \subseteq \tau(e) \wedge t_{T T}<t_{0}$

\section{Aspectual coercion}

In this section, we will review cases in which the selection restrictions of the aspectual operators are not met at a first glance. We will show that these cases can be made acceptable in terms of aspectual coercion, which also explains the wide range of interpretations associated with both aspectual operators.

\subsection{The aorist}

The interpretations of (2) and (3), repeated here as (22) and (23), respectively, emerge as an attempt to avoid an impending mismatch between the selection restriction of the aorist and the aspectual class of its argument in terms of an intervening coercion operator that maps unbounded predicates onto bounded ones.

$\begin{array}{lll}\text { Apothenēisk-ei } & d{ }^{\prime} & \text { oun } \\ \text { die.IPFV.PRS-3sG } & \text { and } & \text { then } \\ \text { Mario-s } & (\ldots) & \text { kai } \\ \text { Marius-NOM.SG } & & \text { and }\end{array}$




$\begin{array}{lll}\text { mega } & e \text {-sch-e } & \text { parautika } \\ \text { great.NOM.SG } & \text { PST-have.AOR-3SG } & \text { immediately } \\ t \bar{e}-n & \text { Romm } \bar{e}-n & \text { charma } \\ \text { the-ACC.SG } & \text { Rome-ACC.SG } & \text { joy.NOM.SG } \\ \text { kai } & \text { tharso-s } & \\ \text { and } & \text { courage-NOM.SG } & \end{array}$

'Then Marius dies ... and immediately, great joy and courage took ossession (AOR) of Rome.'

Plu. Mar. 46.5

(23) allē-n

other-ACC.SG

oudemia-n

no-ACC

en

in

e-bouleu-sa

PST-be.a.senator-AOR.1SG men

PRT

pōpote

ever

$t \bar{e} i$

the.DAT.SG

de

but

'I never held any other office in the state but I served a term as senator (AOR).'

Pl. Ap. $32 \mathrm{a} 9$

For example (22), the inchoative interpretation of the second clause emerges through the insertion of an ingressive coercion operator INGR:

(24) $\operatorname{INGR}(P)(e)$ iff $e$ is the smallest eventuality such that $\neg \exists e^{\prime} . e^{\prime} \supset \prec e \wedge P\left(e^{\prime}\right)$ and $\exists e^{\prime \prime} . e \supset \prec e^{\prime \prime} \wedge P\left(e^{\prime \prime}\right)$

INGR resembles Dowty's change-of-state operator BECOME. INGR $(P)$ holds for smallest eventualities $e$ that do not abut on a preceding eventuality (relation ' $\supset \prec$ ') of type $P$ but abut on a following eventuality in the extension of $P$.

The semantics of the second sentence of (22) is thus analysed as (25). In this analysis, the semantics of great joy and courage is neglected and merely rendered as property $\mathbf{G J C}$ :

(25) $\exists x \exists e . \mathbf{G J C}^{\prime}(x) \wedge \operatorname{INGR}\left(\operatorname{possess}^{\prime}\left(x\right.\right.$, rome $\left.\left.^{\prime}\right)\right)(e) \wedge \tau(e) \subseteq t_{T T} \wedge t_{T T}<t_{0}$

In prose: $t_{T T}$ (the moment immediately after Marius' death) is before the moment of utterance $t_{0}$ and includes the runtime of the beginning of a state, viz., that Rome was possessed by great joy and courage.

Ingressive interpretations for unbounded predicates are mentioned in the literature for examples like (26) (Dowty 1979). These examples show that Moens and Steedman's (1988) schema of aspectual coercions must be extended with coercions that take stative predicates as input:

(26) Suddenly/At six o'clock, I knew the answer

For (23), the relevant coercion operator introduces the notion of a maximal span for which a predicate holds. We formalise this notion in terms of the operator MAX, which just like INGR maps unbounded onto bounded predicates: 


$$
\operatorname{MAX}(P)(e) \text { iff } P(e) \wedge \operatorname{CONV}(e) \wedge \forall e^{\prime} . e \sqsubset e^{\prime} \rightarrow \neg P\left(e^{\prime}\right)
$$

MAX maps a predicate $P$ on the set of locally maximal eventualities in the extension of $P$, which are convex (uninterrupted). It is similar in spirit to Krifka's (1989) operator AOR and to Löbner's (1989) notion of S-phase.

For convex eventualities $e$, any eventuality between parts of $e$ is also part of $e^{10}$ :

$$
\operatorname{CONV}(e) \text { iff } \forall e^{\prime}, e^{\prime \prime}, e^{\prime \prime \prime} \cdot e^{\prime} \sqsubset e \wedge e^{\prime \prime} \sqsubset e \wedge e^{\prime}<e^{\prime \prime \prime}<e^{\prime \prime} \rightarrow e^{\prime \prime \prime} \sqsubset e
$$

Based on this formalisation, the second clause of (23) gets the interpretation in (29), where MAX models the intuition that a term of Socrates serving as a senator (within a topic time that precedes the moment of utterance) is at stake:

$$
\exists e \cdot \operatorname{MAX}\left(\text { be-senator }^{\prime}\left(\text { speaker }^{\prime}\right)\right)(e) \wedge \tau(e) \subseteq t_{T T} \wedge t_{T T}<t_{0}
$$

On the basis of the analyses of the example sentences (22) and (23), we can now answer the question of how it is possible to pursue two seemingly conflicting goals for the analysis of the aorist, viz., accounting for its wide range of interpretations and giving it a nonempty semantic representation. The coercion part of our proposal accounts for the leeway in interpreting aorist clauses, but we are nevertheless not forced to assume that the aorist morphology is semantically empty: It introduces the notion of topic time and relates the runtime of eventualities (as denoted by its semantic argument, a property of eventualities) to the topic time.

This line of analysis can explain the wide range of interpretations associated with the aspectual markers, but does not by itself answer the question of what guides the choice between several applicable coercion operators for a given constellation of aspectual operator and predicate - any coercion operator should be fine as long as it mediates the mismatch between aspectual operator and predicate. This is the Achilles' heel of all coercion analyses. We will not attempt to resolve it fully, but will give a partial answer to the question in Sect. 6 .

\subsection{The imperfective}

In this section we will first show in detail how coercion can result in a progressive or an iterative interpretation of imperfective aspect. In a second part, we will compare the resulting analysis with the one sketched in Bary (2009a), which will yield further insights in the motivation of our approach.

For the imperfective, coercion takes place whenever it is combined with a bounded predicate. Different operators are available, which all map a bounded onto an unbounded predicate. In this paper, we illustrate this with examples that make use of a progressive and an iterative operator. We start the discussion with a

\begin{tabular}{|c|c|c|c|}
\hline $\begin{array}{l}\text { aute } \\
\text { she.NOM.SG }\end{array}$ & $\begin{array}{l}\text { to- } n \\
\text { the- } A C C \text { SG }\end{array}$ & $a n d r$ & $\begin{array}{l}e \text {-thapt-e } \\
\text { PST-bury IPFV-3 }\end{array}$ \\
\hline
\end{tabular}
progressive reinterpretation as illustrated by $(30)[=(5)]$ :

Soph. Ant. 402

\footnotetext{
${ }^{10}$ We assume that there are also non-convex eventualities, e.g., paying a bill in monthly instalments or attending a weekly course.
} 
The topic time in this example (immediately after a cloud of dust had disappeared, see pag. 3) is a part of the runtime of the eventuality of burying introduced by ethapte 'was burying'. To express this temporal constellation and at the same time comply with the selection restriction of the imperfective for unbounded predicates, a progressive operator PROG is used.

PROG maps properties of eventualities onto properties of eventualities: $\operatorname{PROG}(P)$ holds for an eventuality $e$ iff $e$ is part of another eventuality $e^{\prime}$ in the extension of $P$. This second eventuality need not take place in the real world; its status is widely discussed under the heading of imperfective paradox. ${ }^{11}$

The resulting semantic analysis for (30) is (31), which asserts that a burial of a unique man by Antigone was ongoing during the whole topic time, which lies before the utterance time. This correctly does not entail that the burying was completed, since the progressive of a predicate $P$ only entails that a part of an eventuality in the extension of $P$ took place $^{12}$ :

$$
\exists e . \operatorname{PROG}\left(\text { bury }^{\prime}\left(\text { Antigone }^{\prime}, \imath x \cdot \mathbf{m a n}^{\prime}(x)\right)\right)(e) \wedge t_{T T} \subseteq \tau(e) \wedge t_{T T}<t_{0}
$$

The next example (32) $[=(6)]$ resolves the mismatch between imperfective aspect and bounded predicate (suffer defeat) in terms of an iterative operator:

$\begin{array}{lll}\text { Epi } & \text { gar } & \text { Leont-os } \\ \text { during } & \text { PRT } & \text { Leon-GEN.SG } \\ \text { basileuont-os } & k a i & \text { Hégēsikle-os } \\ \text { be.king.IPFV.PTCP-GEN.SG } & \text { and } & \text { Hegesicles-GEN.SG } \\ \text { en } & \text { Spartēi } & \text { t-ous } \\ \text { in } & \text { Sparta.DAT.SG } & \text { the-ACC.PL } \\ \text { all-ous } & \text { polem-ous } & \text { eutucheont-es } \\ \text { other-ACC.PL } & \text { war-ACC.PL } & \text { be.successful.IPFV.PTCP-NOM.PL } \\ \text { hoi } & \text { Lakedaimoni-oi } & \text { pros } \\ \text { the.NOM.PL } & \text { Lacedaemonian-NOM.PL against } \\ \text { Tegeét-as } & \text { moun-ous } & \text { pros- } \text { - } \text {-ptai-on } \\ \text { Tegean-ACC.PL } & \text { only-ACC.PL } & \text { to.PST.bump.IPFV-3PL }\end{array}$

'For when Leon and Hegesicles were kings of Sparta, the Lacedaemonians, while successful in all their other wars, suffered defeats (IPFV) only against the Tegeans.'

Hdt. 1.65.1

Formally, we model iterativity in terms of the operator ITER, which maps predicates $P$ onto the unbounded predicate of being the fusion $\bigsqcup E$ of a set $E$ of maximal $P$ eventualities. A fusion of $E$ is the smallest entity $e$ that comprises all elements of $E$ :

$$
\begin{aligned}
& \operatorname{ITER}(P)(e) \text { iff } \exists E . e=\bigsqcup E \wedge \forall e^{\prime} \cdot e^{\prime} \in E \rightarrow \operatorname{MAX}(P)\left(e^{\prime}\right) \\
& e=\bigsqcup E \text { iff } \forall e^{\prime} \cdot e^{\prime} \in E \rightarrow e^{\prime} \sqsubseteq e \wedge \forall e^{\prime \prime}\left(\forall e^{\prime} \cdot e^{\prime} \in E \rightarrow e^{\prime} \sqsubseteq e^{\prime \prime}\right) \rightarrow e \sqsubseteq e^{\prime \prime}
\end{aligned}
$$

\footnotetext{
11 This topic lies outside the scope of this paper; see e.g. Dowty (1979) and Landman (1992) for in-depth discussions of the problem.

12 We represent definite descriptions in terms of the iota operator: The expression $i x . P(x)$ refers to an entity in the extension of $P$ and introduces the presupposition that $P$ is a singleton set.
} 
Then the semantic analysis of the main clause of (32) is given in (35), which expresses a series of defeats of the Lacedaemonians against the Tegeans, the runtime of whose fusion comprises the topic time (which lies before the utterance time): ${ }^{13}$

\section{(35) $\exists e . \operatorname{ITER}\left(\right.$ suffer_defeat ${ }^{\prime}\left(\right.$ Lacedaemonians $^{\prime}$, Tegeans $\left.\left.{ }^{\prime}\right)\right)(e) \wedge t_{T T} \subseteq \tau(e) \wedge t_{T T}<t_{0}$}

In this analysis, progressive interpretations of the imperfective are analysed as the result of a coercion process that avoids an impending mismatch for bounded predicates that are the argument of the imperfective operator. This analysis differs from the one in Bary (2009a), who assumes no aspectual selection restriction for the imperfective, but assigns to the imperfective a semantics that directly yields a progressive interpretation.

She bases her analysis on Dowty's (1979) progressive operator, which we call $\mathrm{PROG}_{D}$ to distinguish it from the not yet specified operator PROG introduced earlier in this section. Dowty's account of the progressive uses so-called inertia worlds, which are exactly like the world in which the progressive is evaluated until the end of the entity of which the progressive is predicated (Dowty formalises these entities as temporal intervals $I$ ), and in which the course of events develops from that moment on in a way that is maximally compatible with the prior course of events:

(36) $\operatorname{PROG}_{D} \phi$ holds for $\langle I, w\rangle$ iff there is an interval $I^{\prime}$ of which $I$ is a non-final subinterval, and for all inertia worlds $w^{\prime}, \phi$ holds for $\left\langle I^{\prime}, w^{\prime}\right\rangle$.

Bary (2009a) uses this operator as the basis for her operator IMP'. But as an aspectual operator, IMP' maps (intensionalised) properties of eventualities onto (intensionalised) properties of times: ${ }^{14}$

(37) $\operatorname{IMP}^{\prime}(P)(w, t)$ iff in all inertia worlds $w^{\prime}$ with respect to $w$ and $t$ there is an eventuality $e$ such that $P(e)$ and $t$ is a non-final part of $\tau(e)$

For (30), the resulting analysis is thus (38) (neglecting the world parameter), which asserts that in all inertia worlds, the topic time is a non-final part of the runtime of a burial of the unique man by Antigone:

$\operatorname{IMP}^{\prime}\left(\right.$ bury $^{\prime}\left(\right.$ Antigone $\left.\left.^{\prime}, \imath x \cdot \mathbf{m a n}^{\prime}(x)\right)\right)\left(t_{T T}\right) \wedge t_{T T}<t_{0}$

\footnotetext{
13 There is a small complication if one assumes discontinuous (non-convex) eventualities, e.g., if breaks between subeventualities in an iteration are not part of the fusion that constitutes the iterative eventuality as a whole. Then the runtime of such eventualities would be discontinuous as well, which preserves the homomorphism between eventualities and their runtimes.

Consequently, the notion of temporal inclusion relevant for aspectual semantics would have to be generalised accordingly. E.g., for the imperfective, $t_{T T} \subseteq \tau(e)$ would have to be replaced by $\operatorname{INIT}(\tau(e)) \leq \operatorname{INIT}\left(t_{T T}\right) \wedge \operatorname{FIN}\left(t_{T T}\right) \leq \operatorname{FIN}(\tau(e))$, where INIT and FIN map (closed) entities onto their initial and final boundary, respectively, and ' $\leq$ ' is temporal identity or precedence. For convex eventualities $e$, this definition boils down to temporal inclusion.

${ }^{14}$ In contrast, PROG and $\mathrm{PROG}_{D}$ map properties of events on times, respectively, onto the same kind of properties.
} 
For bounded predicates like (30) with a progressive interpretation, this analysis captures the same intuitions as the one advocated in this paper. ${ }^{15}$

For all other stative interpretations of the imperfective, on the other hand, in particular, stative imperfectives as in (4) and habitual interpretations as in (7), the analyses are different in that Bary's analyses would include a progressive operator, while the ones proposed in this paper do not. Bary claims that for an analysis of the progressive in terms of inertia worlds, this inclusion is harmless, since vacuous: Her analyses entail the ones proposed here, because the progressive of a stative predicate (in a literal reading or a habitual reinterpretation) entails the predicate itself.

To decide between the two analyses, one would want to identify cases for which they yield non-equivalent representations. This is the case with process predicates (i.e. unbounded, non-stative predicates), since the analysis of this paper predicts that the eventuality may but need not continue after the topic time (both in the normal and in the actual course of events), whereas Bary's account predicts that it needs to continue after the topic time (in the normal course of events). In absence of clear examples at this point, however, this does not help to decide between the two analyses.

Since the empirical evidence remains inconclusive, our choice for the analysis of the imperfective in (21-a) is based on other arguments. First, this analysis runs in parallel with the one for the aorist: Both aspects introduce a temporal relation and select for a certain aspectual class of predicates. This maximises the common ground between the aspectual operators. Second, Bary's analysis of imperfective statives only works for specific theories of the progressive. E.g., in the analyses of Landman $(1992,2008)$, which also intend to address problems for Dowty's inertiaworld analysis, the progressive of statives would not be well-formed right from the start. I.e., any analysis that can do without stative predicates in the progressive is more flexible in the choice of theory of the progressive. And, finally, the analysis advocated in this paper offers a more parsimonious semantic representation of the imperfective aspect. The drawback is that more interpretations are attributed to coercion than in Bary's account.

\section{The role of the Duration Principle}

So far, we have motivated the need to reinterpret the aorist of unbounded predicates and the imperfective of bounded predicates as an attempt to avoid impending violations of aspectual selection restrictions of the aspectual operators. What we have not addressed up to now, however, is the choice of coercion operator. From the viewpoint of aspectual semantics, any operator would do that maps an unbounded onto a bounded predicate or vice versa. In this section, we will show how the

\footnotetext{
15 There are two minor differences: (1) Bary's analysis models the relation between $t_{T T}$ and $\tau(e)$ in terms of proper part. (2) The present analysis uses both an imperfective and a progressive operator whereas Bary's has only a progressive operator. Hence, we assume temporal inclusion of $t_{T T}$ in the runtime of an entity in the extension of the progressive of a predicate $P$, Bary assumes temporal inclusion of $t_{T T}$ in the runtime of a $P$-eventuality.
} 
Duration Principle (DP) of Egg (2005) guides the choice of coercion operators in these cases. This principle is independent of impending violations of aspectual selection restrictions, hence, can even trigger coercion of its own even if no aspectual selection restrictions are violated.

The DP states that properties of eventualities must be compatible with respect to the duration they attribute to an eventuality. This information may be exact (as in for five minutes) or take the form of a 'typical duration' (e.g., we know that the duration of playing a sonata usually is measured in minutes, but not seconds, or days).

The role of the DP in coercion is due to the fact that coercion operators may influence duration. E.g., an ingressive operator shortens, and a habitual operator lengthens, the typical duration introduced by its argument. There are two ways in which the DP influences coercion.

First, it can guide the choice between several potential coercion operators that are equally useful to avoid an independently established impending aspectual mismatch: The need to ensure compatibility with respect to the duration attributed to an eventuality may guide the choice among these coercion operators in cases of aspectual class coercion. Egg (2005) illustrates this on examples like (39) and (40):

(39) Amélie played the Flying Dutchman for several minutes

(40) Amélie played the Flying Dutchman for several years

The interpretation of (39) is that Amélie played a part of the opera, whereas (40) is interpreted as a repetition of the opera. This difference can be explained by the Duration Principle: First, we assume that a progressive operator influences the typical duration in that the typical duration of $\operatorname{PROG}(P)$ can be shorter than the one of $P$ itself. E.g., the typical duration of playing the Flying Dutchman is in the range of hours, but its progressive can have a typical duration in the range of minutes only. Consequently, a progressive reinterpretation is chosen for (39), which introduces the notion of a part of an eventuality of opera playing, which entails that only part of the opera was played. This is due to the 1-1 relation between subeventualities and opera parts played at these subeventualities, which can be formalised as a homomorphism from opera-playing eventualities to operas along the lines of Krifka (1992).

Analogously, if we assume that an iterative or a habitual operator lengthens the typical duration of its argument, they emerge as potential operators for the coercion in (40). Since iteration directly expresses a repetition of a specific kind of eventuality, and habituality is based on such a repetition, too (assuming that something can only be a habit of Amélie if she indulges in this activity with at least a certain frequency), the aspectual coercion in the case of (40) can use an iterative or a habitual operator in order to comply with the DP, both of which introduce the notion of repetition. ${ }^{16}$

\footnotetext{
${ }^{16}$ The notion of habituality is formalised in different ways in the literature, e.g., in terms of generic quantification (Krifka et al. 1995) over eventualities or quantification over stages (Carlson 1977) of individuals (Rimell 2004). In any formalisation, there must be a sufficient number of instances of eventualities of a specific type that gives rise to a habit.
} 
Second, the DP can trigger coercions of its own, if there is incompatible temporal information on an eventuality in an otherwise well-formed sentence (that in particular exhibits no impending aspectual mismatch). Examples of Egg (2005) include (41), in which an iterative interpretation aligns the typical durations expressed in the modifier for the whole summer and play soccer on the beach, whose typical duration would otherwise be too short to match the one of the adverbial. Note that no aspectual coercion is called for in this example, since for-adverbials select for unbounded predicates, and play soccer on the beach is unbounded:

(41) Amélie played soccer on the beach for the whole summer

The French example (42) $[=(10)]$ is an instance of a purely DP-related coercion, too.

(42) Quand j' étais petit, je ne dormais pas bien.

When I be.IP.1sG young I not sleep.IP.1sG not well

'When I was young I didn't sleep (IP) well.'

The imperfective requires the time of sleeping uneasily to be included into the topic time (the youth of the speaker), and the typical duration of such sleeping eventualities is too short for that. Consequently, a habitual coercion, which may considerably lengthen the typical duration, is called for: The runtime of the habit of sleeping uneasily can be long enough to include the whole youth of the speaker. Again, this coercion is not motivated by aspectual considerations.

We will now review these two domains of influence of the DP for Ancient Greek, starting with the function of the DP as a guide for aspectual coercion.

\subsection{The DP as a guide for aspectual coercion}

The DP in its role as a guide for the selection of coercion operators for independently motivated aspectual coercion is relevant for the coercion of an unbounded predicate in the aorist. While from an aspectual point of view both ingressive and complexive reinterpretation would be possible in (22), its interpretation is clearly ingressive. In this example, the topic time is very short, because parautika 'immediately' fixes the topic time as a time point. Since the aorist requires proper or improper inclusion of the runtime of the eventuality into the topic time, coercion in terms of an ingressive operator is called for, as it returns an eventuality (the beginning of joy and courage) of very short duration whose runtime can be improperly contained in $t_{T T}$. Complexive coercion would not be possible because the runtime of a maximal eventuality of being glad and courageous, including its beginning and ending, would not fit within a time point.

Compare this to the interpretation of (23), in which the topic time (Socrates' whole previous life) is considerably longer. In this case, a complexive coercion is possible, because $t_{T T}$ can comprise the runtime of serving a term as senator from begin to end.

For bounded predicates $P$ in the imperfective, the DP is relevant for cases in which the topic time exceeds the typical duration associated with the predicate (recall that the imperfective requires inclusion of $t_{T T}$ in the runtime of the 
eventuality introduced by $P$ ). In these cases, a progressive reinterpretation is ruled out, because the typical duration for $\operatorname{PROG}(P)$ does not exceed the one of $P$.

E.g., in (32), the bounded predicate pros Tegeètas monous proseptaion 'to suffer a defeat (literally, to bump into) only against the Tegeans' could not receive a progressive reinterpretation, since the topic time (the reign of Leon and Hegesicles over Sparta) could not fit into the runtime of an eventuality characterised by the progressive of this predicate. In contrast, an iteration of losing against the Tegeans can have a runtime that is long enough to comprise the time of the reign of Leon and Hegesicles.

The interpretation of (30) works differently. Here the topic time (the time immediately after the cloud of dust had disappeared) is so short that a progressive reinterpretation is possible: the progressive of ton andr' ethapte 'to bury the man' introduces a runtime that is long enough to contain $t_{T T}$.

We will now turn to cases in which there is no aspectual mismatch but nevertheless coercion, which was triggered exclusively by the intension to avoid an impending DP violation.

\subsection{The DP as a trigger for coercion}

For predicates in the imperfective, the DP is in danger of being violated if the topic time is extremely long: According to the imperfective, the topic time must fit in the runtime of the predicate, and, if the typical duration of the predicate is too short to accommodate the topic time, reinterpretation is called for.

Such a constellation was noted for the French (42) and can likewise be found in sentence $(43)[=(7)]$ :

$\begin{array}{llll}\text { en } & \text { dexia- } i & \text { de } & k a i \\ \text { in } & \text { right-DAT.SG } & \text { PRT } & \text { and } \\ \text { en } & \text { aristera- } i & \text { autou } & \text { te } \\ \text { in } & \text { left-DAT.SG } & \text { him.GEN } & \text { PRT } \\ k a i & t \text {-ōn } & \text { hippe-ōn } & \text { peltasta-is } \\ \text { and } & \text { the-GEN.PL } & \text { cavalry-GEN.PL } & \text { targeteer-DAT.PL } \\ \text { chōra } & \bar{e} n & & \\ \text { place.NOM.SG } & \text { be.PST.IPFV.3SG } & & \end{array}$

'To the right and left from him and the cavalry was (IPFV) the usual place for the targeteers.'

X. Cyr. 8.5.10

Its topic time is the time during which Cyrus waged wars, i.e., years, and therefore exceeds the typical duration of targeteers being in a specific strategic position. With a habitual operator the impending DP mismatch can then be avoided, because it considerably lengthens the typical duration (habits may well last for years). This coercion leaves the aspectual class of the predicate untouched, which proves that no aspectual class coercion has taken place.

In sum, this section showed that aspectual reinterpretation is guided by the independently operating Duration Principle. This is a first step in trying to explain how the leeway introduced through reinterpretation does not lead to much ambiguity for concrete instances of reinterpreted predicates. 


\section{Conclusion and further work}

In this paper, we presented an account of the variation in interpretation of the Ancient Greek imperfective and aorist. Following Klein (1994) and Gerö and Stechow (2003), among others, Ancient Greek aspect establishes a relation between the topic time and the runtime of the eventuality described by the predicate. Imperfective aspect indicates that the topic time is included in the time of the eventuality, whereas aoristic aspect indicates the reverse relation: The time of the eventuality is included in the topic time. This yields the basic opposition between imperfective and aoristic aspect. Apart from expressing a temporal relation to the topic time, however, both aspects introduce aspectual selection restrictions. Imperfective aspect selects for unbounded predicates, aoristic aspect for bounded ones. We showed how both restrictions can be motivated in terms of pragmatic strengthening, which removes semantic overlap between competing instantiations of the same grammatical feature (here, aspect).

If the restrictions of the aspects are not met by the predicate, coercion comes into play: Intervening reinterpretation operators resolve the aspectual mismatch. We showed how this leads to the progressive, iterative, and habitual interpretations of imperfective aspect, and the ingressive and complexive interpretations of the aorist. The Duration Principle plays an important role in guiding the choice between the various reinterpretation operators, and also triggers coercions of its own.

We conclude this section with pointers to further research questions, starting with the issue of what guides the choice of reinterpretation operators. While we have shown that the Duration Principle goes some way in explaining this choice, we do not wish to claim that it explains the choice in its entirety.

First, conventionalisation of coercion plays an important role: At some point, the repertoire of aspectual coercion operators becomes standardised, which severely restricts the range of possible reinterpretations. While this immediately raises the question of how such a conventionalisation comes about, it is definitely there, which makes it possible to compile (most probably, language-specific) lists of feasible aspectual coercion operations as e.g. in Moens and Steedman (1988).

What is more, we sometimes feel that the choice of coercion operator is influenced by the specific context of the sentence to be coerced. Reconsider for instance (23), which is a case of complexive coercion. The DP itself would not prevent an ingressive coercion for this sentence, because the topic time is the previous life of Socrates, which could encompass the runtime of Socrates' whole term as a senator just as easily as the runtime of the beginning of this term. But in the given context (Socrates having to defend himself and trying to adduce evidence in his favour), it makes much more sense to assume a complexive coercion: Only his term as a senator as a whole (and his conduct during that period) and not the mere beginning of such a term could provide evidence in favour of his personality. Eventually, this kind of argumentation falls back on inferences on the basis of Gricean (1975) conversation maxims (here, relevance).

Similarly, (8) can be explained in terms of context: The sentence that follows the sentence to be coerced explicitly rules out that the transaction got started, let alone has been finished already. This rules out a habitual or iterative coercion of oneeto 'bought', leaving only a progressive or a conative coercion. We feel that such an 
argumentation that turns on the general underspecification and context-dependence of language can explain why aspectual coercion is an extremely flexible process that does not introduce unwanted ambiguity for contextually situated utterances, however.

There are some issues left for future research. One concerns the conative interpretation of imperfective aspect, as in (8). We would like to leave open at this point whether this interpretation can be dealt with in terms of the progressive operator or should be assigned a coercion operator of its own. On the one hand, it is tempting to analyse it as a special case of the progressive interpretation, viz., a progressive interpretation with agentive predicates like oneeto 'bought' (those that include an agent in their thematic roles). This would directly yield the interpretation of an attempt: The agent is busy performing the action described by the verb, but as long as the action has not been completed, the agent's activity only qualifies as an attempt to perform this action.

In order to model the fact that the eventuality denoted by the predicates not only has not been completed, but need not even have started, one could further assume that verbs that occur with the conative interpretation, like oneeto 'bought', are punctual (denote eventualities with extremely short runtimes). In that way, the conative interpretation would be very similar to English cases of the progressive with punctual predicates, as in (44). Here the progressive takes the preparatory phase rather than the actual reach eventuality as its input Moens and Steedman (1988), which yields the interpretation that a process whose result will be the reaching of the top is ongoing:

(44) Mary was reaching the top

This approach, however, would leave unexplained why (8) cannot be translated with a progressive in English ('he was buying'), which suggests that the two are not exactly the same. A broader cross-linguistic comparison of conative interpretations may be of use here.

Finally, on a more general level, the present analysis should be supplemented with an account of how topic times are introduced, accessed, and updated in a discourse. While Bary (2009a) formulates the default rules for sequences of main clauses and Bary and Haug (2011) investigate the role of participles, the contribution of other kinds of clauses and discourse structure (often indicated by particles) is still to be investigated for Ancient Greek.

Acknowledgments We thank Emar Maier, Henriëtte de Swart, Peter de Swart, and an anonymous reviewer for their comments on earlier versions of this paper.

Open Access This article is distributed under the terms of the Creative Commons Attribution License which permits any use, distribution, and reproduction in any medium, provided the original author(s) and the source are credited.

\section{References}

Asher, N., \& Lascarides, A. (2003). Logics of conversation. Cambridge: Cambridge University Press. Bary, C. (2009a). Aspect in Ancient Greek: A semantic analysis of the aorist and imperfective. Ph.D. thesis, Radboud University Nijmegen. 
Bary, C. (2009b). The perfective/imperfective distinction: coercion or aspectual operators? In

L. Hogeweg, H. de Hoop, \& A. Malchukov (Eds.), Cross-linguistic semantics of Tense, Aspect and Modality (pp. 33-53). Amsterdam: John Benjamins.

Bary, C. (to appear). The Ancient Greek tragic aorist revisited. Glotta.

Bary, C., \& Haug, D. (2011). Temporal anaphora across and inside sentences: The function of participles. Semantics and Pragmatics, 4, 1-56.

Bennett, M., \& Partee, B. (1978). Toward the logic of tense and aspect in English. Bloomington: Indiana University Linguistics Club.

Carlson, G. (1977). A unified analysis of the English bare plural. Linguistics \& Philosophy, 1, 413-457. de Swart, H. (1998). Aspect shift and coercion. Natural Language and Linguistic Theory, 16, 347-385.

Dowty, D. (1979). Word meaning and Montague grammar. Dordrecht: Reidel.

Egg, M. (2005). Flexible semantics for reinterpretation phenomena. Stanford: CSLI Publications.

Gerö, E.-C., \& Stechow, A. v. (2003). Tense in time: The Greek perfect. In R. Eckardt, K. v. Heusinger, \& C. Schwarze (Eds.), Words in time: Diachronic semantics from different points of view (pp. 251-294). Berlin: de Gruyter.

Gricean, P. (1975). Logic and conversation. In P. Cole \& J. Morgan (Eds.), Syntax and semantics 3: Speech acts (pp. 41-58). New York: Academic Press.

Klein, W. (1994). Time in language. London: Routlege.

Krifka, M. (1989). Nominalreferenz und Zeitkonstitution. München: Fink.

Krifka, M. (1992). Thematic roles as links between nominal reference and temporal constitution. In I. Sag \& A. Sabolcsi (Eds.), Lexical matters (pp. 29-53). Stanford: CSLI.

Krifka, M., Pelletier, F., Carlson, G., ter Meulen, A., Chierchia, G., \& Link, G. (1995). Genericity: an introduction. In G. Carlson \& F. Pelletier (Eds.), The generic book (pp. 1-124). Chicago: University of Chicago Press.

Landman, F. (1992). The progressive. Natural Language Semantics, 1, 1-32.

Landman, F. (2008). 1066. On the differences between the tense-perspective-aspect systems of English and Dutch. In S. Rothstein (Ed.), Theoretical and Cross-linguistic Approaches to the Semantics of Aspect (pp. 107-166). Amsterdam: Benjamins.

Löbner, S. (1989). German schon - erst - noch: An integrated analysis. Linguistics \& Philosophy, 12, 167-212.

Moens, M., \& Steedman, M. (1986). Temporal information and natural language processing. Technical Report Research Paper RP-2, CCS, University of Edinburgh.

Moens, M., \& Steedman, M. (1988). Temporal ontology and temporal reference. Computational Linguistics, 14, 15-28.

Rimell, L. (2004). Habitual sentences and generic quantification. In G. Garding \& M. Tsujimura (Eds.), WCCFL 23 Proceedings. Somerville: Cascadilla Press.

Smyth, H. (1920). A Greek grammar for colleges. New York: American Book Company. 